\title{
Technical-economic evaluation of medium-power gas turbine plant with air bottoming cycle
}

\author{
Alexey V. Mikheev ${ }^{1, *}$, Yulia M. Potanina ${ }^{1}$ \\ ${ }^{1}$ Melentiev Energy Systems Institute of Siberian Branch of the Russian Academy of Sciences
}

\begin{abstract}
A developed mathematical model of a gas turbine power plant with an additional air bottoming cycle to utilize heat of exhaust gases was used to carry out a technical and economic analysis. The approach used in the study is aimed at solving two types of optimization problems: (1) to determine the maximum net efficiency of the power plant and (2) to adjust the equipment and operating parameters for achieving minimum costs of electricity production. The study shows that the air bottoming cycle provides an increase in the net efficiency up to $44-48 \%$ and adds about $20 \%$ to the installed power capacity. The minimum costs of electric energy production estimated for different prices of fuel (natural gas) are competitive enough, so the gas turbine power plant with air bottoming cycle seems to be a promising technology for medium-power generation.
\end{abstract}

Keywords. Gas turbine, air bottoming cycle, waste heat recovery, gas-turbine plant, electric power, efficiency.

\section{Introduction}

The electricity generation from fossil fuels, especially natural gas, using gas turbines has been a rapidly developing technology in the last decades. Gas turbines are high-tech power units operating with an initial gas temperature of up to $1500{ }^{\circ} \mathrm{C}$, a high compression ratio of about 30 and the overall efficiency of up to $30-40 \%$ and above. At the same time, the simple-cycle gas turbines (without an additional bottoming steam cycle), despite a lower electrical efficiency, are also widely used for covering peak loads and for flexible maneuverable generation in the consumer segment of small and medium power plants, including autonomous power supply systems.

In Russia, the main needs of power generation expansion in the nearest decades primarily relate to gas turbines in the medium power class $(25-100 \mathrm{MW})$ almost $20 \mathrm{GW}$ by 2025 and more than $40 \mathrm{GW}$ by 2040 [1]. Such forecast reflects a trend in recent years as an increase of own distributed generation in companies.

Modern gas turbine units of the medium power range from 25 to $100 \mathrm{MW}$ are characterized by high electrical efficiency. Based on the data from [2] for gas-turbine equipment, the electric efficiency (gross efficiency) of gas-turbine units at a rated load of medium-power plants reaches $43-44 \%$.

The temperature of the exhaust gases at the gas turbine outlet (or after the cascade of turbines) is still about 400 $540^{\circ} \mathrm{C}$, which causes a significant loss of exergy. There are many technologies for using heat of exhaust gases: regenerative heating of compressed air; regenerative water heating for steam injection into a turbine or compressor; the use of an additional steam cycle for the production of thermal or electric energy in combinedcycle power plants [3].

One more technology for the use of waste heat from the gas turbine exhaust gases is the additional air bottoming cycle (GT-ABC). Instead of a combustion chamber for additional heating of the compressed air in compressor, an air-gas heat exchanger is used, in which heated air is used to remove the heat excess from exhaust gases. Then an air turbine converts the energy of the

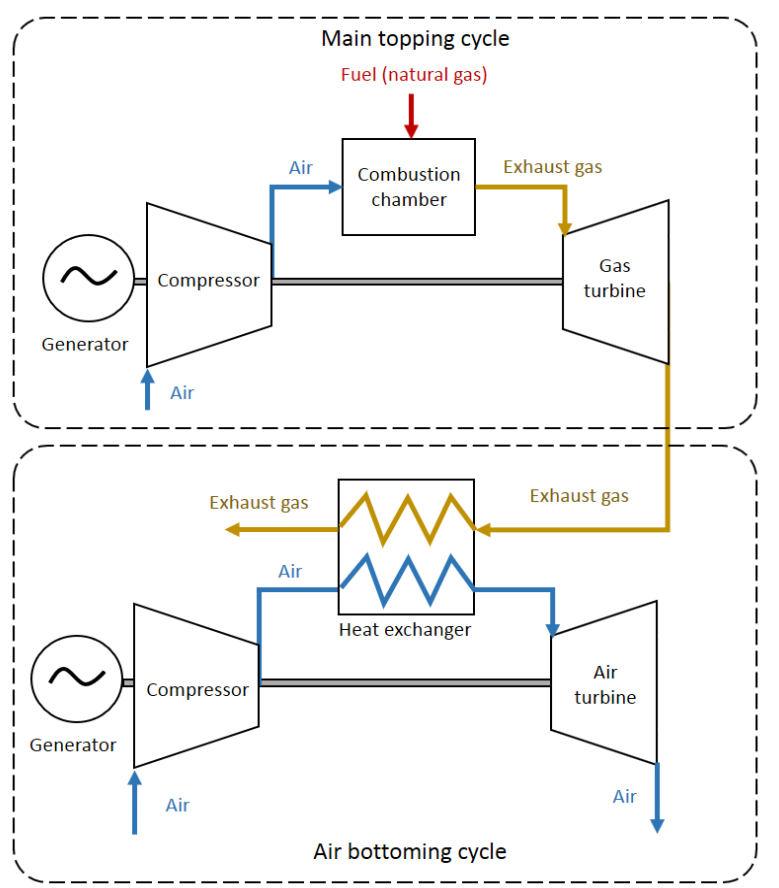

Fig. 1. General scheme of gas turbine unit with air bottoming cycle (GT-ABC). 
exhaust gases from the main cycle of a gas turbine into mechanical energy to generate additional electrical energy.

The main advantage of a GT-ABC power plant is the simplicity of its implementation. The level of complexity of the technological scheme and the equipment used in GT-ABC is comparable to conventional gas turbine unit. Widely used schemes for heat recovery of exhaust gases based on various options of the steam turbine cycle involve more complex and expensive low-grade equipment (steam recovery boiler, steam turbine, condenser, pumps, cooling and water treatment systems) increasing capital and operating costs. The ease of implementation of the power plant directly affects its economic efficiency. An increase in the useful installed power capacity of gas turbines with the same fuel consumption and a small increase in capital costs can be a decisive factor for decision making.

The performance of GT-ABC has been repeatedly studied. The authors of [4] show that GT-ABC with a multistage compressor and intermediate air coolers at various compression ratio achieve optimal operating conditions at a gas turbine inlet temperature of $1400 \mathrm{~K}$, the air compression ratios of the main and additional compressors are 10 and 2, respectively. It is shown that the overall efficiency of the installation can reach $49 \%$, which gives a gain of $23 \%$ compared to a simple-cycle gas turbine and the electrical power of the unit increases by almost 30\%.

In [5], the authors propose the configurations of GT$\mathrm{ABC}$ scheme improved by steam and water injection into the air bottoming cycle. The study shows that the overall efficiency of GT-ABC increases by $2.6-4.8 \%$ and the specific work increases by $6.7-11.7 \%$ compared to the standard GT-ABC scheme. The net efficiency exceeds $50 \%$, which is a significant achievement for the simple cycle.

In [6], an exergy analysis of $\mathrm{GT}+\mathrm{ABC}$ is presented with a compression ratio of the air bottoming cycle equal to 6 and at different temperatures of the external air and gas at the inlet of the turbine and compression ratios of the main cycle.

The authors of [7] compare the marginal cost of electric energy generated by various commercially available gas turbines such as Taurus 60, Titan 130 and UGT 25000, which are integrated into two bottoming utilization cycles based on air or steam (combined cycle).

In [8], a thermodynamic analysis of the performance of a combination of topping and bottoming cycles of GT$\mathrm{ABC}$ scheme was carried out for various air compression ratios from 3 to 15 in the main gas turbine cycle and from 3 to 12 in the additional bottoming cycle. The analysis reveals that the average increase in plant capacity is about $27 \%$, although the efficiency of GT-ABC is lower than that of a gas turbine with a steam cycle. Continuing the study, in [9], the authors investigate the effectiveness of different advanced technological schemes based on GT$\mathrm{ABC}$ that represent various combinations of several technologies (like a steam cycle and absorption cooling) for utilizing the heat of exhaust gases.

The most comprehensive technical-economic review with optimization of a gas turbine with air bottoming cycle is presented in [10] to evaluate simple and water injected air bottoming cycles against steam bottoming cycles.

This paper presents additional research to evaluate technical-economic parameters of $\mathrm{GT}+\mathrm{ABC}$ for a class of medium power plants of 25-60 MW.

\section{Modeling principles and initial conditions}

A generalized mathematical model of GT-ABC unit has been developed using the "Thermal schemes modeler software" [11]. The model calculates the basic thermodynamic characteristics of a gas turbine, such as air compression ratio, pressure, gas and air temperature. Standard models of equipment components from the "Thermal Schemes Modeler" software library were used to calculate thermodynamic parameters of the compressor, turbine and combustion chamber of the main and air cycles of gas turbine engines. The simplified gas turbine model is used without modeling the cooling of the flow part.

The special assessment model was added to the scheme to calculate the net efficiency of the power plant and the parameters of its economic efficiency. The assessment of the GT-ABC cost-effectiveness is based on the calculation of the total investment and life-cycle operating costs of GT-ABC. The costs include:

- costs of the electricity generators;

- costs of main equipment;

- construction costs;

- costs depending on the amount of fuel consumed;

- operating costs depending on the total period of use.

Investments in individual components of a gas turbine are estimated through the specific unit costs of gas and air turbines, air compressors, electric generators, gas-air heat exchangers (per unit area).

The methodology for assessing the economic efficiency through solving the non-linear optimization problem is described in [12]. Studying power plants, the authors of [13] propose the optimization problems of several types. Here, for the considered power plant, such problems include:

Problem 1. Maximization of the net efficiency of the power plant (or minimization problem for specific fuel consumption).

Problem 2. Minimization of the cost of electric energy at a given value of the internal rate of investment return.

A typical scheme of $\mathrm{GT}+\mathrm{ABC}$ describing the initial characteristics is initially assigned to solve the optimization problems. The values of the parameters are presented in Table 1. To determine the total investment in gas turbines, specific unit costs are set for different types of equipment. The values of the parameters are assigned based on an expert review and cost analysis of various components of the equipment of existing and prospective power plants. The outside average temperature is accepted as recommended for Russia $-15^{\circ} \mathrm{C}$. The installed capacity level of GT-ABC is set through the fuel consumption in the combustion chamber to be $2 \mathrm{~kg} / \mathrm{s}$, which ensures an annual fuel consumption of 60228 toe. This flow rate is typical for a class of medium power plants. 
Table 2 provides a list of the main optimized parameters and physical and technical limitations on their values.

The air compression ratio is one of the key parameters of the compressor equipment efficiency. The maximum value for the topping cycle is 40 , and for the air bottoming cycle is 30 .

The increase in gas temperature at the inlet of the gas turbine directly affects the high efficiency of the power unit. The upper-temperature limit is due to the heat resistance of the gas turbine materials. For large-scale gas turbines, a temperature of about $1600{ }^{\circ} \mathrm{C}$ was reached. When considering low-cost plants of medium power, one should focus on maximum temperatures of about $1300^{\circ} \mathrm{C}$.

Table 1. Input parameters for technical-economic evaluation.

\begin{tabular}{|c|c|}
\hline Parameter & Value \\
\hline Annual fuel consumption for GT-ABC, toe & 60228 \\
\hline Internal relative efficiency of air compressors, $\%$ & 85 \\
\hline Internal relative efficiency of gas turbine, $\%$ & 90 \\
\hline Capacity utilization time per year, hours & 7000 \\
\hline Plant operating life, years & 30 \\
\hline Compressor inlet air temperature, $\mathrm{K}$ & 288 \\
\hline Internal rate of return, $\%$ & 12 \\
\hline \multicolumn{2}{|l|}{ Specific costs of equipment: } \\
\hline - air compressors, US $\$ . / \mathrm{kW}$ & 54 \\
\hline - turbines, US\$/kW & 72 \\
\hline - heat exchanger pipe material, US\$/kg & 30.6 \\
\hline $\begin{array}{l}\text { - fuel consumption dependent equipment, US\$ / } \\
\text { (kg / hour) }\end{array}$ & 100 \\
\hline
\end{tabular}

Table 2. List of main optimized parameters and their boundary conditions.

\begin{tabular}{|l|c|c|}
\hline \multicolumn{1}{|c|}{ Parameter } & $\begin{array}{c}\text { Minimal } \\
\text { value }\end{array}$ & $\begin{array}{c}\text { Maximum } \\
\text { value }\end{array}$ \\
\hline Main topping cycle: & 0.8 & 4 \\
\hline $\begin{array}{l}\text { - air pressure at the air } \\
\text { compressor outlet, MPa }\end{array}$ & 0.104 & 0.15 \\
\hline $\begin{array}{l}\text { - gas pressure at the gas } \\
\text { turbine outlet, MPa }\end{array}$ & 1000 & 1573 \\
\hline $\begin{array}{l}\text { - gas temperature at the } \\
\text { combustion chamber outlet, } \mathrm{K}\end{array}$ & & \\
\hline Air bottoming cycle: & 50 & 800 \\
\hline $\begin{array}{l}\text { - air flow to an air turbine, } \\
\text { kg/s }\end{array}$ & 0.3 & 3 \\
\hline $\begin{array}{l}\text { - air pressure at the air } \\
\text { compressor outlet, MPa }\end{array}$ & & \\
\hline $\begin{array}{l}\text { - air pressure at the air turbine } \\
\text { outlet, MPa }\end{array}$ & 0.103 & 0.18 \\
\hline Gas-air heat exchanger: & \multicolumn{2}{|l}{} \\
\hline - air mass flow rate, ${ }^{3 / s}$ & 30 & 100 \\
\hline - gas temperature drop, K & 5 & 200 \\
\hline - outer diameter of pipes, $\mathrm{m}$ & 0.03 & 0.04 \\
\hline - inner diameter of pipes, $\mathrm{m}$ & 0.018 & 0.028 \\
\hline - pipe pitch, $\mathrm{m}$ & 0.045 & 0.07 \\
\hline
\end{tabular}

The gas pressure after gas turbine of the topping cycle and the air pressure after the air bottoming turbine shows the degree of expansion of the working fluid and thus determines the effective work of the turbines.

The efficiency of the gas-air heat exchanger determines the working characteristics of the additional bottoming cycle. To optimize heat transfer in the exchanger, air mass flow rate and temperature drop (the difference between gas and air temperatures) are important. The metal consumption on heat transfer surfaces determines the total cost of the element.

Optimization studies consisted of two parts. Firstly, a feasibility study was performed to solve problem 1 of maximizing net efficiency. The objective of solving the problem is to determine the maximum achievable limits of the technical efficiency of GT-ABC. However, the operation of a heat and power plant aimed at ensuring maximum efficiency may be economically unprofitable, since there can be a significant increase in specific investment in expensive equipment.

The second part of the studies was to find a solution to problem 2 , i.e. a minimum electricity production cost at a given fuel price. Three fuel price options are considered - US\$ 143, 214 and 286 per tonne of oil equivalent. The grid of fuel price options corresponds to the range of fluctuations in average natural gas prices from approximately US\$ 115 to US\$ 230 per $1000 \mathrm{~m}^{3}$ of natural gas at prices of 2018 for domestic and foreign industrial consumers.

\section{Results and discussion}

Table 3 presents the thermodynamic parameters of the main topping cycle, air bottoming cycle and gas-air heat exchanger obtained as a result of solving the above optimization problems. The results show that for the main cycle, the technological limit on the gas temperature at the gas turbine inlet has been reached. For low-cost solutions in the field of high-temperature gas turbines, this limit can be increased to achieve higher total efficiency.

The air temperature at the outlet of the air turbine of the bottoming cycle is still about $250-315{ }^{\circ} \mathrm{C}$. The temperature difference between the air already heated in the heat exchanger and the gases leaving the turbine is about $75-100{ }^{\circ} \mathrm{C}$ and characterizes the final loss of exergy. The heat losses can be utilized by adding another recovery bottoming cycle or regenerative heater.

As shown in Table 6, the total net power of GT-ABC plant is from 44 to $48 \mathrm{MW}$. The additional power received from the implementation of the air bottoming cycle is more than $7 \mathrm{MW}$ or almost $20 \%$ of the total power capacity. The cost for additional air cycle equipment is about a third of the capital investment in the plant equipment.

Maximum net efficiency of GT-ABC is equal to $48,29 \%$ and net power output of the plant is $48.33 \mathrm{MW}$. The efficiency becomes a little less when solving the problem of finding a minimum cost of electric energy produced. It increases with an increase in fuel prices in the range from 44 to $46 \%$ as shown in Fig. 2 . In any case, the efficiency remains $4-6 \%$ higher than that of the most effective simple-cycle gas turbine units. 
Table 3. List of key thermodynamic parameters of GT-ABC.

\begin{tabular}{|c|c|c|c|c|}
\hline \multirow{4}{*}{ Parameter } & \multicolumn{4}{|c|}{ Value } \\
\hline & \multirow{3}{*}{$\begin{array}{c}\text { For a } \\
\text { maximum } \\
\text { of net } \\
\text { efficiency }\end{array}$} & \multicolumn{3}{|c|}{$\begin{array}{c}\text { For a minimum of } \\
\text { electricity cost }\end{array}$} \\
\hline & & \multicolumn{3}{|c|}{ Fuel prices, US\$ / toe } \\
\hline & & 143 & 214 & 286 \\
\hline \multicolumn{5}{|l|}{ Gas topping cycle } \\
\hline $\begin{array}{l}\text { Air flow to } \\
\text { compressor, } \mathrm{kg} / \mathrm{s}\end{array}$ & 100.3 & 86.7 & 88.9 & 90.6 \\
\hline $\begin{array}{l}\text { Air pressure at } \\
\text { compressor outlet, } \\
\text { MPa }\end{array}$ & 2.98 & 1.6 & 1.8 & 1.97 \\
\hline $\begin{array}{l}\text { Gas pressure at } \\
\text { combustion } \\
\text { chamber outlet, } \\
\mathrm{MPa}\end{array}$ & 2.86 & 1.53 & 1.73 & 1.89 \\
\hline $\begin{array}{l}\text { Gas pressure at GT } \\
\text { outlet, } \mathrm{MPa}\end{array}$ & 0.104 & 0.106 & 0.106 & 0.106 \\
\hline $\begin{array}{l}\text { Air temperature at } \\
\text { compressor outlet, } \\
\mathrm{K}\end{array}$ & 798.9 & 671.9 & 695.0 & 712.2 \\
\hline $\begin{array}{l}\text { Gas temperature at } \\
\text { combustion } \\
\text { chamber outlet, } \mathrm{K}\end{array}$ & \multicolumn{4}{|c|}{1572.9} \\
\hline $\begin{array}{l}\text { Gas temperature at } \\
\text { GT outlet, K }\end{array}$ & 809.3 & 921.9 & 899.8 & 884.0 \\
\hline \multicolumn{5}{|l|}{ Air bottoming cycle } \\
\hline $\begin{array}{l}\text { Air pressure at } \\
\text { compressor outlet, } \\
\mathrm{MPa}\end{array}$ & 0.425 & 0.368 & 0.382 & 0.385 \\
\hline $\begin{array}{l}\text { Air pressure at air } \\
\text { turbine inlet, } \mathrm{MPa}\end{array}$ & 0.419 & 0.364 & 0.378 & 0.382 \\
\hline $\begin{array}{l}\text { Air pressure at air } \\
\text { turbine outlet, } \mathrm{MPa}\end{array}$ & \multicolumn{4}{|c|}{0.103} \\
\hline $\begin{array}{l}\text { Air temperature at } \\
\text { air turbine outlet, } \\
\mathrm{K}\end{array}$ & 526.9 & 615.4 & 595.6 & 586.0 \\
\hline \multicolumn{5}{|c|}{ Gas-air heat exchanger } \\
\hline $\begin{array}{l}\text { Gas temperature } \\
\text { drop, } \mathrm{K}\end{array}$ & 75.8 & 97.3 & 93,8 & 88,7 \\
\hline $\begin{array}{l}\text { Air mass flow rate, } \\
\mathrm{m}^{3} / \mathrm{s}\end{array}$ & 30.2 & 39.6 & 37,4 & 35,4 \\
\hline $\begin{array}{l}\text { Outer pipe } \\
\text { diameter, } \mathrm{m}\end{array}$ & 0.039 & 0.03 & 0,03 & 0,03 \\
\hline $\begin{array}{l}\text { Inner pipe } \\
\text { diameter, } \mathrm{m}\end{array}$ & 0.018 & 0.028 & 0,028 & 0,028 \\
\hline Pipe pitch, $\mathrm{m}$ & 0.05 & 0.046 & 0,045 & 0,045 \\
\hline $\begin{array}{l}\text { Outlet gas } \\
\text { temperature, } \mathrm{K}\end{array}$ & 458.2 & 567.8 & 543,0 & 529,7 \\
\hline $\begin{array}{l}\text { Outlet gas } \\
\text { pressure, } \mathrm{MPa}\end{array}$ & 0.103 & 0.103 & 0,103 & 0,103 \\
\hline $\begin{array}{l}\text { Inlet air } \\
\text { temperature, } \mathrm{K}\end{array}$ & 453.0 & 433.1 & 438,1 & 439,4 \\
\hline $\begin{array}{l}\text { Outlet air } \\
\text { temperature, } \mathrm{K}\end{array}$ & 733.4 & 824.6 & 805,9 & 795,3 \\
\hline Air flow, $\mathrm{kg} / \mathrm{s}$ & 133.9 & 86.0 & 94,0 & 97,9 \\
\hline
\end{tabular}

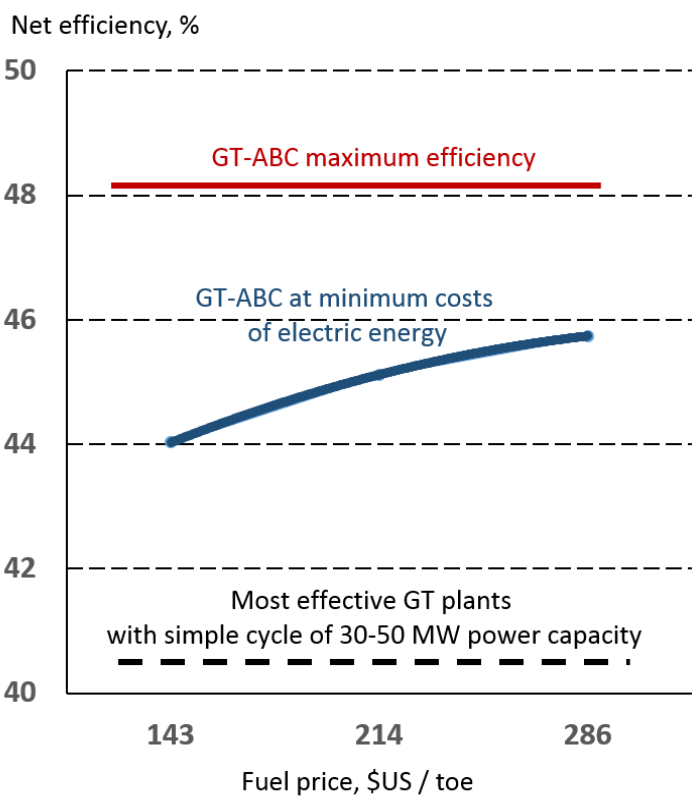

Fig. 2. Comparison of GT-ABC performance vs. most effective simple-cycle gas turbine power plants.

Specific investment in the GT-ABC power plant is about $633-680$ US\$ / kW. Converting USD taken from the price of natural gas in 2018, we can compare the specific investments with the level of investment in the existing simple-cycle and combined-cycle gas turbine plants given in [2]. Such a comparison for gas turbines in the class of small and medium power up to $100 \mathrm{MW}$ is shown in Fig. 3. It can be seen from the Figure that the specific investments in the power capacity of GT-ABC are exactly between the cheaper simple-cycle gas turbine plants and more expensive combined-cycle gas turbine plant. In addition, this clearly shows the effect of economies of scale on the cost of the installed capacity.

The results obtained agree well with the thermodynamic efficiency data obtained in the studies by other authors [5], [8]. In these studies, the efficiency of the GT-ABC power plant for the gas temperature at the gas turbine inlet of $1300{ }^{\circ} \mathrm{C}$ reaches $49 \%$. The optimal air compression rate in the topping cycle is also within the range of 15-30. The greater efficiency was obtained probably due to the high internal relative efficiencies of turbines and compressors.

\section{Conclusions}

A technical and economic analysis of gas turbine power plant with air bottoming cycle (GT-ABC) was carried out as a combination of two types of optimization problems. The optimization aimed at determining the maximum net efficiency and adjusting the optimal configuration of equipment and operating conditions to achieve the minimum costs of electricity for three fuel price levels US\$ 143, 214 and 286 per tonne of oil equivalent. An analysis of the results showed that the maximum 
Table 4. Main results of a technical-economic evaluation of GT-ABC.

\begin{tabular}{|c|c|c|c|c|}
\hline \multirow{4}{*}{ Parameter } & \multicolumn{4}{|c|}{ Value } \\
\hline & \multirow{3}{*}{$\begin{array}{c}\text { For a } \\
\text { maximum } \\
\text { of net } \\
\text { efficiency }\end{array}$} & \multirow{2}{*}{\multicolumn{3}{|c|}{$\begin{array}{c}\text { For a minimum of electricity cost } \\
\text { Fuel prices, US\$ / toe }\end{array}$}} \\
\hline & & & & \\
\hline & & 143 & 214 & 286 \\
\hline Overall performance, $\%$ & 48,29 & 44,03 & 45,12 & 45,74 \\
\hline Capital investment in installed capacity, US\$ / kW & - & 633,0 & 660,5 & 680,6 \\
\hline Lowest cost of electric energy, US\$ / MWh & - & 47,8 & 61,6 & 75,1 \\
\hline Annual electricity output, GWh & 338,3 & 308,5 & 316,1 & 320,4 \\
\hline $\begin{array}{l}\text { Fuel (natural gas) consumption for electricity production, toe / } \\
\text { GWh }\end{array}$ & 178,0 & 195,2 & 190,5 & 188,0 \\
\hline
\end{tabular}

\section{$\mathrm{US} \$ / \mathrm{kW}$}

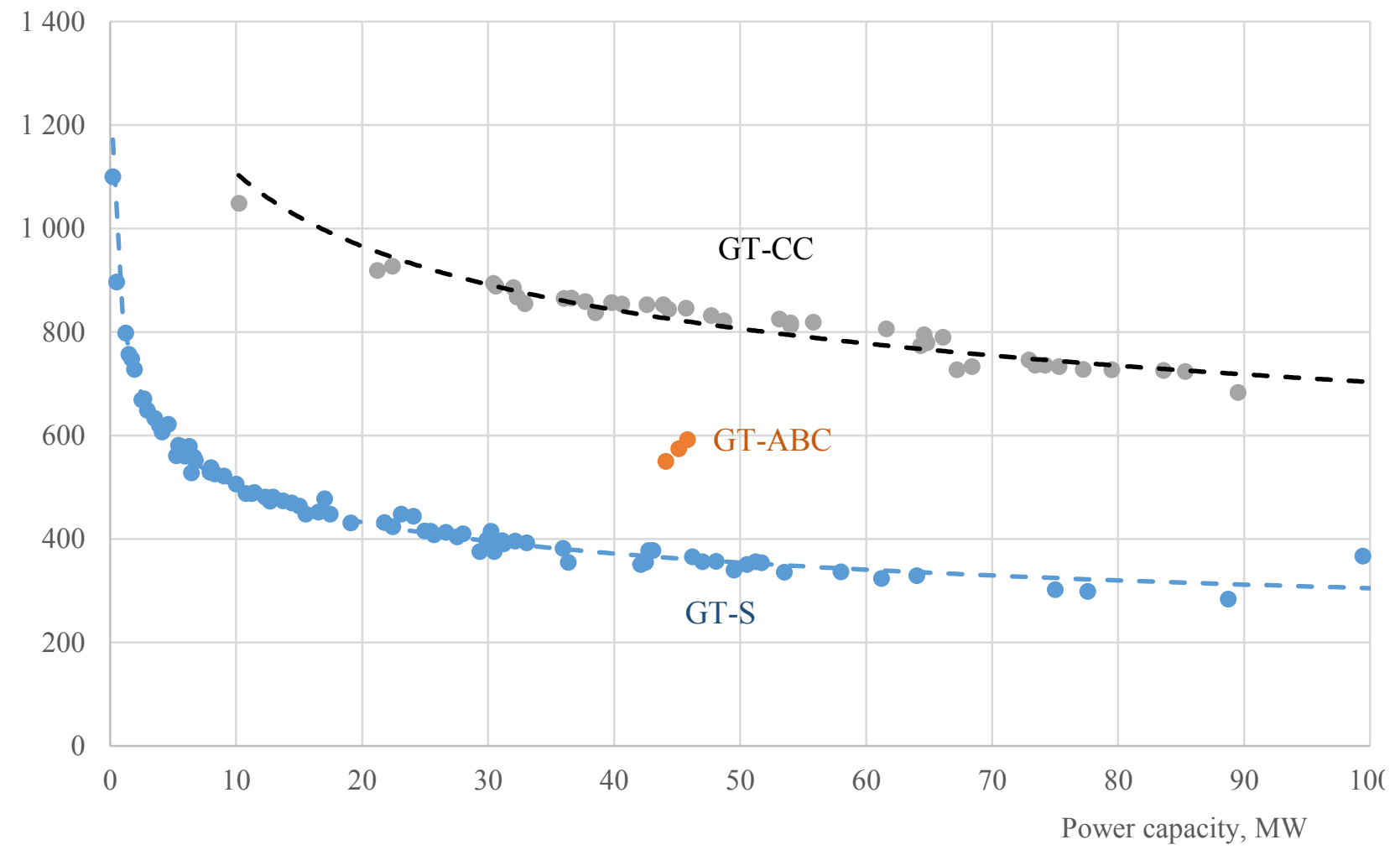

Fig. 3. The specific cost of installed power capacities for GT-CC (combined cycle), GT-ABC (air bottoming cycle) and GT-S (simple cycle) based on the evaluation and data from [2].

achievable efficiency of the power plant is $48.3 \%$ at the gas turbine inlet temperature about $1300^{\circ} \mathrm{C}$ within compression ratio of 16 to 30 . The efficiency according to the criterion of minimum electric energy costs is about 44$46 \%$. In this case, the useful power added through waste heat recovery is about $20 \%$. The results are in good agreement with the data of other researchers. Specific investments in the power plant are between simple- and combined-cycle gas turbine plants. The lowest costs of electric energy are estimated at 47.8 - 75.1 US\$ / MWh depending on fuel prices. That is quite competitive for Russia at the current market prices for natural gas. Further, it is necessary to make a more detailed system comparison of advanced GT-ABC schemes taking into account the innovative technological development.
The work was carried out under State Assignment, Project 17.1.1 (reg. number AAAA-A17-117030310433-6) of Fundamental Research of Siberian Branch of the Russian Academy of Sciences.

\section{References}

1. Filippov S. P., Dil'man M. D., Ionov M. S. Demand of the power industry of Russia for gas turbines: the current state and prospects. Thermal Engineering, 64(11), (2017), $829-840$. https://doi.org/10.1134/S0040601517110052

2. Gas Turbine World 2012 GTW Handbook // Pequot Publication, Volume 29. (2012). 63 pp. 
3. Modern gas turbine systems. Eds. P. Jansohn, Woodhead Publishing, (2013) 842 p. ISBN 978-1-84569728-0.

4. Najjar Y., Zaamout M.S. Performance analysis of gas turbine air-bottoming combined system. Energy Conversion Management, 37(4), (1996) pp. 399 -403.

5. Ghazikhani M, Passandideh-Fard M, Mousavi M. Two new high-performance cycles for a gas turbine with air bottoming. Energy, (2011). 36:294e304.

6. Ghazikhani M, Khazaee I, Abdekhodaie E. Exergy analysis of gas turbine with air bottoming cycle. Energy (2014); 72:599e607.

7. Chmielniak T, Czaja D, Lepszy S, StepczynskaDrygas K. Thermodynamic and economic comparative analysis of air and steam bottoming cycle. Energy (2015); 92:189e96.

8. Alklaibi A.M., Khan M.N., Khan W.A. Thermodynamic analysis of gas turbine with air bottoming cycle. Energy, 107, (2016). pp. 603-611.

9. Alklaibi A.M. Utilization of exhaust gases heat from the gas turbine with air bottoming combined cycle. Energy, 133, (2017). pp. 1108-1120.

10. Saghafifar M., Gadalla M. A critical assessment of thermo-economic analyses of different air bottoming cycles for waste heat recovery. International Journal of Energy Research, 43(4), 1315-1341. (2019). https://doi.org/10.1002/er.4243

11. Thermal schemes modeler. Software. URL: http://www.thermalmodeler.ru Accessed: June 10, 2019.

12. Kler A. M., Zakharov Y. B., Potanina Y. M. Coordinated optimization of the parameters of the cooled gas-turbine flow path and the parameters of gas-turbine cycles and combined-cycle power plants. Thermophysics and Aeromechanics, 21(3), 383-392. (2014). https://doi.org/10.1134/s0869864314030111

13. Kler A.M., Potanina Yu.M., and Maksimov A.S. Accounting for the variable nature of heat loads in optimizing cogeneration combined heat and power plants. Thermal Engineering, , Vol. 59, No. 7, (2012). P. 550-556. 